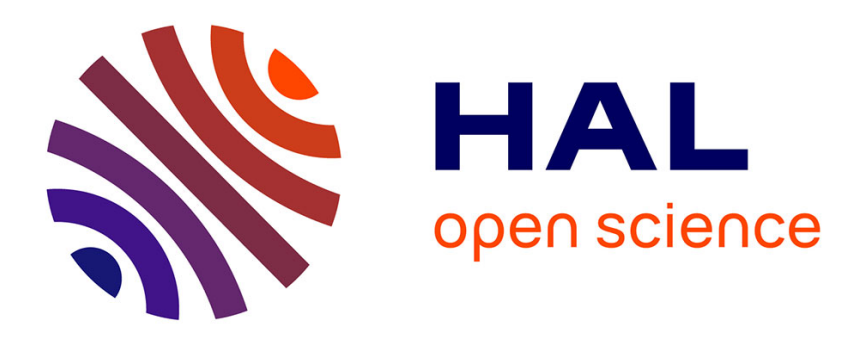

\title{
A model of Factors Influencing the Supply Chain Performance
}

\author{
Omar Sakka, Valerie Botta-Genoulaz
}

\section{To cite this version:}

Omar Sakka, Valerie Botta-Genoulaz. A model of Factors Influencing the Supply Chain Performance. 2009. hal-00389134

\author{
HAL Id: hal-00389134 \\ https://hal.science/hal-00389134 \\ Preprint submitted on 28 May 2009
}

HAL is a multi-disciplinary open access archive for the deposit and dissemination of scientific research documents, whether they are published or not. The documents may come from teaching and research institutions in France or abroad, or from public or private research centers.
L'archive ouverte pluridisciplinaire HAL, est destinée au dépôt et à la diffusion de documents scientifiques de niveau recherche, publiés ou non, émanant des établissements d'enseignement et de recherche français ou étrangers, des laboratoires publics ou privés. 


\title{
A model of Factors Influencing the Supply Chain Performance
}

\author{
Omar Sakka ${ }^{1}$, Valérie Botta-Genoulaz ${ }^{2}$ \\ Université de Lyon, INSA-Lyon, LIESP \\ ${ }^{1}$ LIESP, 7, avenue Jean Capelle, Bât Blaise Pascal, F-69621 Villeurbanne, France, \\ omar.sakka@insa-lyon.fr \\ ${ }^{2}$ dpt GI, 19, avenue Jean Capelle, Bât Jules Verne, F-69621 Villeurbanne, France, \\ valerie.botta@insa-lyon.fr
}

\begin{abstract}
Improvement of industrial performance such as cost, lead-time, adaptability, variety and traceability is the major finality of companies. Thus, they need to collaborate and to strengthen their coordination mechanisms. Information exchange, supply chain practices and inter-organizational collaboration becomes then strategic issues: what is the nature of the information that can be shared with customers and suppliers? Which impact on the performance of a company is expectable? What is about the performance of the whole supply chain? It is essential for a company to identify the information whose exchange contributes to its performance, to control its information flows and to redefine its relationships with its partners. This study aims to release from the literature the main tendencies of collaboration practices and information exchanges leading to the performance and to propose a model of their relations.
\end{abstract}

Keywords: supply chain, performance, practices, collaboration, information exchange

\section{INTRODUCTION}

To face the strong pressures of the world competition, companies are constantly in search of new ways to improve the performance of their supply chain in order to reduce costs, to improve quality and to increase productivity. To go from an activity centred on the product to an activity, which must permanently meet the needs for the other members of the, chain is not an easy change. The borders of a company are then exceeded so that the other partners are regarded as members of a wide structure. However to exchange/share information, competences with other actors of the chain is not easy. To meet this organizational change, it is necessity for the companies to strengthen significantly their mechanisms of coordination and collaboration. Then, information sharing and collaborative practices become strategic questions.

In this study, we are interesting in identifying, at first, the main factors and practices of information exchange and collaboration which can contribute to the supply chain performance in general and the supply chain actors performance individually, and in the second time, to build a generic model which is based on these various factors. We realized a bibliographical study relating to information exchange and collaboration practices, which lead to the performance, in order to identify checked or unchecked relations of cause and effect. From this study, we propose a model of factors influencing supply chain performance.

The following section is devoted to the bibliographical study where we analyze the main recent research works dealing with the subject. A synthesis and a classification of the factors contributing to the performance of supply chains are proposed in section 3. In section 4, we present the generic model gathering all factors that contribute to the performance, such as information exchanges and collaboration practices. In section 5, we highlight some strong points of the study and offer suggestions for future research.

\section{LITERATURE REVIEW}

Companies try to improve their industrial performance in terms of cost, delays, adaptability, variety and traceability. Collaboration and information exchange between partners becomes essential within any supply chain.

Many works seek how to improve the performance of the supply chains. We based our study on the main recent research works in order to emphasize factors contributing to supply chains performance. Authors try through their models and hypothesis to reinforce collaboration and cooperation devices that contribute to company or supply chain performance. We find various strategies and contributions based on information technologies, information exchange, information sharing, supply chain practices, inter-organizational communication and collaboration.

Paulraj et al. [1] consider inter-organizational communication as a critical factor for strategic collaboration between companies. They define the inter-organizational communication as a relational competence, which can provide a strategic advantage 
for the partners of the chain and thus improve their performance.

Focused on the collaboration and the use of the information technology, Chen et al. [2] use the CPFR (Collaborative Planning Forecasting and Replenishment), a collection of practices which aims to radically reduce stocks and expenses and also tries to increase the customer service, to simulate four scenarios of collaboration between a retailer and a supplier. The authors show that the use of the IT cannot alone ensure that partners can gain. Mutual trust plays an essential role in achieving this goal.

Always based on the use of information technologies and with the aim to improve other types of performance - the performance of the market and the financial performance - Seggie et al. [3] explore IT alignment and inter-firm system integration between supply chain partners as supply chain specific IT facilitators of brand equity. However, there could be more supply chain facilitators of brand equity including inter-firm coordination, inter-firm information exchange, partner flexibility and inter-firm integration of supply chain activities. The improvement of brand equity influences positively on market and financial performance.

More generally and while always seeking to improve the performance of the company, Sander [4] aims to extend knowledge on how the use of e-business technologies impacts organizational collaboration, and organizational performance. The author proposes a model of the relationship between organizational use of e-business technologies, organizational collaboration, and organizational performance. Indeed, the growth of Information Technology and especially the Internet and the Web may have had the most profound impact on business integration and collaboration. This study confirmed that e-business technology use have a significant direct impact on both intra and inter-organizational collaboration. Another important finding is the significant impact of intra-organizational collaboration on performance. Hence, companies should invest in strategies that promote cooperation and integration across the functions of the organization.

New concepts appeared with Yang et al. [5]. The authors test the links between relational capital, relational commitment, relational stability, and alliance performance. The cooperation in the form of alliance enables firms to share financial risk, improve service quality, increase productivity, and reduce cost. This study shed light on the importance of managing relationships in supply chain alliances in terms of ensuring relational commitment, trust of suppliers, and relational stability to lead the performance.

Other types of performance are considered in the literature such as delivery performance, supplier performance, customer performance, etc. Zhou et Benton [6] investigate the integration of information sharing and supply chain practice in supply chain management. This study focuses on three aspects of information sharing - information sharing support technology, information content, and information quality - and considers three categories of supply chain practice: supply chain planning, just in time (JIT) production, and delivery practice. On the other hand, this research takes an interest in the delivery performance defining by on-time delivery, perfect order fulfilment rate, and delivery reliability/dependability. The result of this study shows that both effective information sharing and effective supply chain practices are necessary to achieve improvement in supply chain performance, and have significant influence on delivery performance.

Other works are interested in testing the influence of other types of practices on the supply chain performance. $\mathrm{Li}$ et al. [7] define supply chain management practices as the set of activities undertaken by an organization to promote effective management of its supply chain, and propose five dimensions of supply chain management practices: strategic supplier partnership, customer relationship, level of information sharing, quality of information sharing, and postponement. These practices influence positively the financial performance, the market performance and create a competitive advantage for the company in terms of price, quality, reliability, product innovation and time to market. Chowa et al. [8] add others practices like communication, integration and customer service management, supply chain concerns, information sharing and specify that even if these practices are different geographically, they influence always positively the total performance of the chain.

Among all the practices studied in the literature, the information exchange and the information sharing remain the most involved practices. Many authors such as [9], [10], [11], [12], [13], [14], [15] and [16] have sought to identify information that may be shared and to evaluate the impact and the profit of these exchanges. We can so release six kinds of information to be exchanged in the supply chain: products, resources, stocks, delays, demands and planning information.

In practice, to improve supply chain performance, executives often choose to implement either effective information sharing or effective supply chain practices because limited resources usually prevent firms from pursuing both simultaneously. As a solution, Zhou and Benton [6] propose the standardization of supply chain processes. The standardization of supply chain processes tends to help companies to take better advantage of the information shared among supply chain partners. Information sharing is a means to capture the supply chain dynamics and thus reduce uncertainty in external and internal environments. When coupled with the standardization inherent in effective supply chain practices, this uncertainty reduction allows performance improvement.

Klein [17] examines supply chain management relationships between service providers and clients, and focuses on the impacts of the provider's information exchange behaviour and both parties' level of trust. Trust has been established as core component of persistent business partnerships and strategic alliances 
[18, 19]. Trust influences cooperation and teamwork within organizations characterized as mutually beneficial initiatives. The relationship between service providers and clients is also based on the level of client customization of integrated supply chain functions through outsource service providers' e-business applications and solutions.

Fynes et al. [20] study the nature of supply chain relationships with the aim of improving customer satisfaction. The authors define the supply chain relationship quality as the degree to which both parties in a relationship are engaged in an active, long-term working relationship, and using indicators of communication, trust, adaptation, commitment, interdependence, and co-operation.

The mutual interest of the works presented above is that they try to improve the supply chain performance while following several strategies or models. The use of information technologies, information exchange, and sharing, inter-organizational communication, trust, cooperation and intra- and inter-organizational collaboration form essential factors of supply chain performance. However a company must be able to clearly define its requirements in performance in order to identify which are the best practices meeting these needs. In the following section, we are going to present more precisely and exhaustively all the factors collected from the literature which we could gather and which lead the performance of the supply chain.

\section{CLASSIFICATION OF FACTORS INFLUENCING THE PERFORMANCE}

According to our literature review, we realize that each study aims to identify the influences of some collaborative or technical practices on one or two types of performance, by testing several hypothesis. The goal of this section is to gather and classify every practice identified in the literature leading to the improvement of the performance.

We could extracted fifty seven hypotheses from the studied research [21], which have been tested by experts of the domain through companies surveys.

To classify these hypotheses, we initially sought to characterize the nature of each of them. That led us to express the hypotheses in the form of "A has a positive effect on B" where $\mathrm{A}$ is a characteristic known as "factor" and B is a characteristic known as "impact/result", by respecting the original idea of the authors. Example: "The use of information technologies has a positive effect on an inter-organizational communication". In this example, "the use of the information technology" is the factor and "the inter-organizational communication" is the impact/result. We found some hypotheses, which were verified and others, which the experiments of the authors did not allow the verification. We state that a hypothesis is verified if the characteristic " $A$ " can generate or improve the characteristic "B". If the characteristic "A" does not generate or does not improve the characteristic " $\mathrm{B}$ ", we say that the hypothesis is not verified (not to confuse with a false hypothesis).

We then gathered the identified characteristics in four main categories: performance characteristics, technical technological characteristics, relational and contextual characteristics and characteristics of the supply chain practices.

\subsection{Performance characteristics}

This class gathers ten characteristics, which represent the various forms of performance quoted in studied work: customer performance, supplier performance, financial performance, market performance, delivery performance, performance of service providers, alliance performance, and organizational performance. The goal is generally to improve these performances. Thus, it happens very often that these characteristics of performance are the "impact / result" characteristics of a tested hypothesis. The global performance of the supply chain is a combination of these various performances.

\subsection{Relational and contextual characteristics}

These characteristics form the big class (seventeen characteristics) because they present the various relationships, which can exist between the actors of the supply chain, and characterize the context, in which evolves the company. These characteristics describe the behaviour, the vision, the type of relationships and interactions between a company and its partners (suppliers or / and customers). Among these characteristics, we quote trust towards the supplier/customer, long-term relationship orientation, inter- and intra-organizational communication, collaboration... Some characteristics can be gathered in subclasses because they concern the same concept: as example the quality of supply chain relationship, the trust, the capacity...

\subsection{Technical and technological characteristics}

This class of eight characteristics is based on the use of information technologies. It gathers the techniques and the technological choices made by a company such as information sharing support technology, inter-firm system integration mode, e-business technologies...

\subsection{Characteristics of supply chain practices}

This class gathers nine characteristics dealing with supply chain practices. These practices have been defined as a set of activities undertaken in an organization to promote effective management of the supply chain [7]. Therefore, we find in this class the practices of information sharing, production, planning, etc.

Table 1 presents the four classes of characteristics and refers to the studied bibliographical sources. Each research work was interested in one or more 
characteristics. On each line, figures represent for every research work the number of hypotheses in which a characteristic appears, either as factor $(F)$ or as result (R).

This table highlights certain interpretations:

- The common goal of all these works is to improve one or several kinds of performance.

- All the authors were more interested in the relational and contextual characteristics.

- The technical and technological characteristics and the characteristics of supply chain practices are rather factors characteristics.

- Almost every author (except one) has studied the relational and contextual characteristics that are rather factors than results.

Table 1. Bibliographical reference synthesis

\begin{tabular}{|c|c|c|c|c|c|c|c|c|}
\hline \multirow{3}{*}{ Ref. } & \multicolumn{8}{|c|}{ Characteristics } \\
\hline & \multicolumn{2}{|c|}{$\begin{array}{l}\text { Technical } \\
\text { and } \\
\text { technological }\end{array}$} & \multicolumn{2}{|c|}{$\begin{array}{c}\mathrm{SC} \\
\text { practices }\end{array}$} & \multicolumn{2}{|c|}{$\begin{array}{c}\text { Relational } \\
\text { and } \\
\text { contextual }\end{array}$} & \multicolumn{2}{|c|}{ Performance } \\
\hline & $\mathbf{F}$ & $\mathbf{R}$ & $\mathbf{F}$ & $\mathbf{R}$ & $\mathbf{F}$ & $\mathbf{R}$ & $\mathbf{F}$ & $\mathbf{R}$ \\
\hline [1] & 2 & & & & 6 & 6 & & 2 \\
\hline [4] & 3 & & & & 2 & 3 & & 2 \\
\hline [5] & & & & & 4 & 3 & & 1 \\
\hline [17] & 5 & 3 & & & 4 & 2 & & 4 \\
\hline [3] & 5 & 5 & & & 4 & 2 & 1 & 3 \\
\hline [22] & & & 1 & & 4 & 4 & & 1 \\
\hline [6] & 1 & & 7 & 2 & 2 & 1 & & 7 \\
\hline [7] & & & 5 & & 5 & 5 & & 2 \\
\hline$[20]$ & & & & & 6 & & 2 & 3 \\
\hline$[8]$ & & & 5 & & & & & 1 \\
\hline Sub-Total & 16 & 8 & 18 & 2 & 37 & 26 & 3 & 26 \\
\hline Total & \multicolumn{2}{|c|}{24} & \multicolumn{2}{|c|}{20} & \multicolumn{2}{|c|}{63} & \multicolumn{2}{|c|}{29} \\
\hline
\end{tabular}

\section{FACTORS MODEL INFLUENCING THE PERFORMANCE}

The identification of the hypotheses studied in the literature and the classification of the characteristics led us to build a detailed model of the factors influencing the performance. We have considered only verified hypotheses.

This model (figure 1) is a directed graph including four types of vertex (a type of vertex for each type of characteristic). A vertex can have one of the following forms: rectangle, round rectangle, hexagon and octagon to present respectively characteristics of supply chain practices, technical and technological characteristics, relational and contextual characteristics and performance characteristics. Each class gathers characteristics, which can be at the same time "factors" (origin of an arrow), and/or "results" (destination of an arrow). The various relations between these elements model the hypotheses: a directed arc between two characteristics, in the same class or not, models a hypothesis. Moreover, one class of characteristics can gather one or more subclasses of characteristics. These subclasses are the semantic grouping of some characteristics.

We can represent the model in an aggregate form (Figure 2) according to the number of arrows connecting a class to another. This global model gathers obviously the four classes of characteristics. Full arrows present the interactions between these various classes, the thickness of the arrow being proportional to the number of hypotheses checked between these classes. As first interpretation, we can notice that the class of characteristics of performance is the "target" class. The class of the relational and contextual characteristics represents the "core" of the model since it interacts with all the other classes. Moreover, it has the greatest influence on the class of performance. Thus, for a company, it is interesting to concentrate on this type of characteristic and to define its relations and its strategies with its partners. So important, the class of the technical and technological characteristics has a rather strong influence on the characteristics of performance. This class also interacts with the class of relational and contextual characteristics but not with the one of supply chain practices. Finally, the class of supply chain practices characteristics has a medium influence on the class of performance and has no relation with the technical and technological characteristics. On the other hand it appears to be rather influenced by the class of relational and contextual characteristics.

The contribution of these two models is double. On one hand for the researchers, these models aggregate various factors of performance (through several types of characteristics: technical, relational...), what is almost absent in the scientific literature. We find generally one or two types of characteristics studied in every research work. In other words, they propose a general sight of the factors contributing to performance and of their weights. On the other hand, these models allow a company to situate itself regarding its collaborative practices and relationships that it keeps with its supply chain partners. These models offer companies knowledge on causal relations between technical / technological, relational / contextual, supply chain practices and performance characteristics. A company may better understand in which direction focusing its efforts: partners' relationship reengineering, information and communication technologies investments... and the limits of some practices for the improvement of its supply chain performance. Moreover, our model reveals many hypotheses, i.e. causal relations, which have not been tested yet.

\section{CONCLUSION}

To remain competitive, any company tries to build a strategy allowing remaining in the best conditions in front of present competitive strengths within its sector. The performance of a company, in terms of cost, quality and delays, depends more and more strongly on its capacity to optimize its relationships with its partners and on its ability to collaborate and to exchange the good information. 


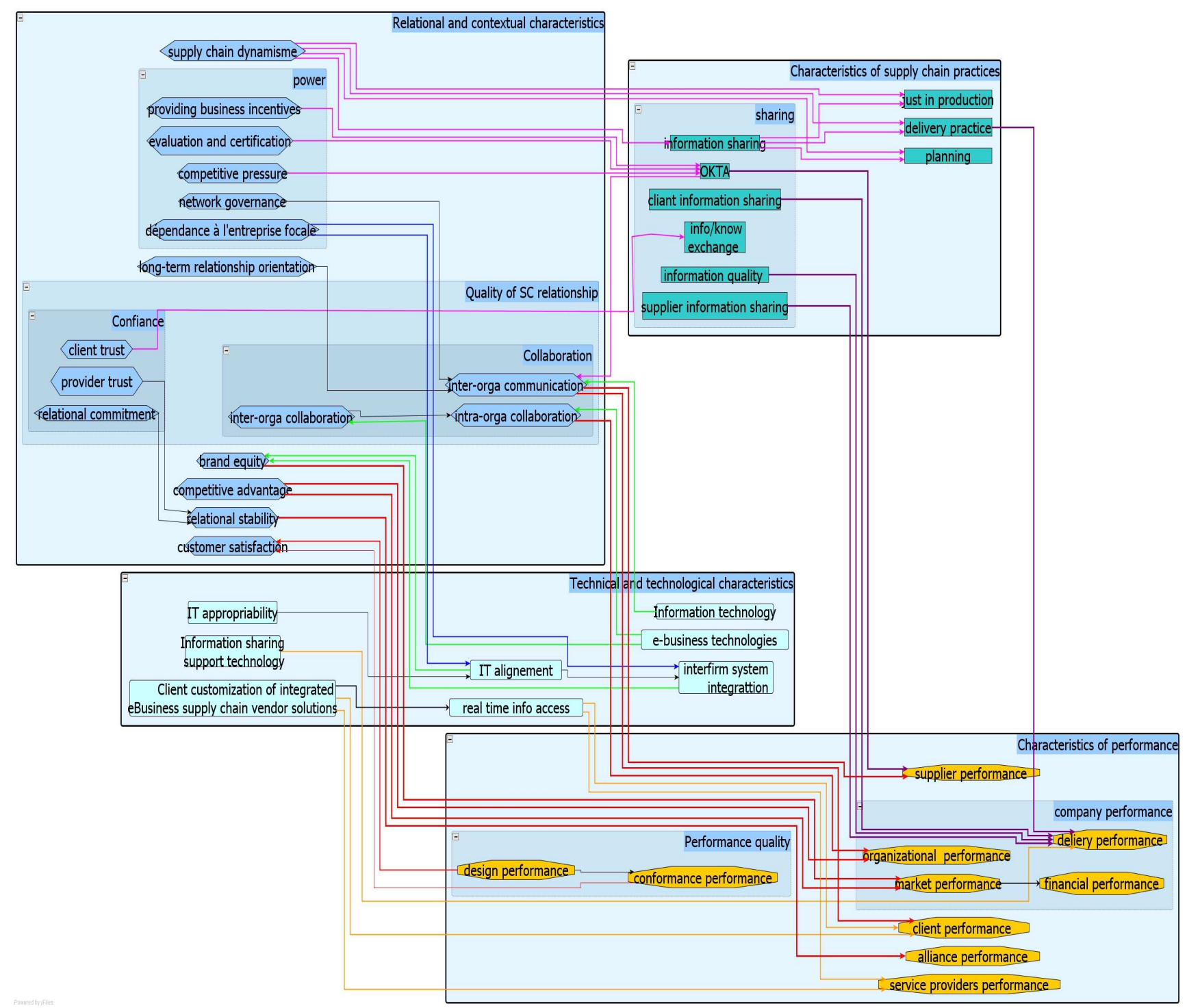

Figure 1. Detailed model of factors influencing the performance

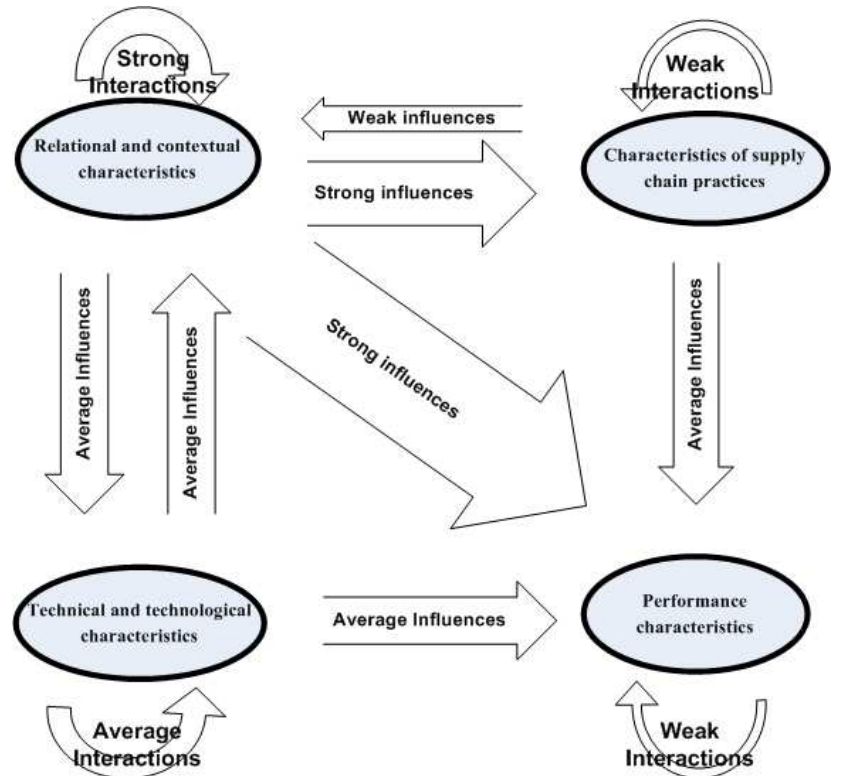

Figure 2. General model
This work has consisted in proposing model of the factors influencing the performance of the various actors in the supply chain.

Based on a review of recent literature, we have identified the main factors, which can contribute to the performance. This performance concerns either each actor of the chain as such, or all the supply chain. We have distinguished the performance of the company, of the supplier, of the customer, as well as the indispensable elements to reach these performances such as the use of information and communication technologies, intra and inter-organizational collaboration, inter-organizational communication, production practices...

Each one of the authors was interested in one aspect of the performance. The proposed model, which gathers 48 hypotheses on 44 characteristics, represents a reference model of factors contributing to the performance of the supply chains for researchers and companies. This model could be of course completed and enhanced by a more complete analysis of the 
literature. Indeed, one can wonder about the role of the other supply chain practices as VMI or CPFR on the performance, and their place in the model.

In terms of perspectives, it would be interesting to test new hypotheses and to study the correspondence between the configuration of a company - such as its global strategy, the characteristics of its products lines - and the collaborative practices, which it puts in place (or wishes to implement) to assure the required coordination between actors for the improvement of their performance.

It would be also interesting to test the transitivity of the relations between the various characteristics; for example, if "A has a positive effect on B" and "B has a positive effect on $\mathrm{C}$ ", could we say, "A has a positive effect on C"? This could give more choices to decision makers and possibly reduce the number of characteristics.

Finally, the notion of hypotheses could be widened to conditional hypotheses. Certain unchecked "simple" hypotheses may be verified under certain conditions: if "A has no positive effect on B", it may be that, by adding factor " $\mathrm{C}$ ", "A, under the condition $C$, has a positive effect on B".

\section{REFERENCES}

[1] Paulraj, A., Lado, A. A., Chen, I. J., (2008) Inter-organizational communication as a relational competency: Antecedents and performance outcomes in collaborative buyer-supplier relationships. Journal of Operations Management, 26, pp. 45-64.

[2] Chen, M. C., Yang, T., Li, H.-C., (2007) Evaluating the supply chain performance of IT-based inter-enterprise collaboration. Information \& Management, 44, pp. 524-534.

[3] Seggie, S. H., Kim, D., Cavusgil, S. T., (2006) Do supply chain IT alignment and supply chain interfirm system integration impact upon brand equity and firm performance? Journal of Business Research, 59, pp. 887-895.

[4] Sanders, N. R., (2007) An empirical study of the impact of e-business technologies on organizational collaboration and performance. Journal of Operations Management, 25, pp. 1332-1347.

[5] Yang, J., Wang, J., Wong, C. Y., Lai., K.-H., (2008) Relational stability and alliance performance in supply chain. The International Journal of Management Science, Omega 36 pp. 600 - 608.

[6] Zhou, H., Benton, W. C. J., (2007) Supply chain practice and information sharing. Journal of Operations Management, 25 pp. 1348-1365.

[7] Li, S., Ragu-Nathan, B., Ragu-Nathan, T. S., Rao, S. S., (2006) The impact of supplychain management practices on competitive advantage and organizational performance. The International Journal of Management Science, 34 (2), pp. 107-124.

[8] Chowa, W. S., Madu, C. N., Kuei, C.-H., Lu, M. H., Chinho, L., Tseng, H., (2008) Supply chain management in the US and Taiwan: An empirical study. The International Journal of Management Science, 36 (5), pp. 665-679.

[9] Gaonkar, R., Viswanadham, N., (2001) Collaboration and information sharing in global contract manufacturing network. Transactions on Mechatronics, 6, pp. 366-376.

[10] Laux, J., Hung, G., Mak, K., (2004) Impact of information sharing on inventory replenishment in divergent supply chains. International Journal of Production Research, 41, pp. 919-941.

[11] Liu, E., Kumar, A., (2003) Leveraging information sharing to increase supply chain configurability. 523-537.

[12] Sahin, F., Robinson, E. P., (2005) Information sharing and coordination in make to order supply chain. Journal of Operations Management, 23, pp. 579-598.

[13] Shore, B., (2001) Information sharing in global supply chain systems. Journal of Global Information Technology Management, pp. 27-50.

[14] Llerena, D., Duvallet, J., Lemarié, S., Penz, B., (2006). Evaluer les impacts du partage d'information: objectif, méthodologie, résultats.www.copilotes.eu [15] Gruat-La-Forme, F.-A., (2007) Référentiel d'évaluation de la performance d'une chaîne logistique: Application à une entreprise de l'ameublement. Thèse de doctorat, INSA de Lyon.

[16] Botta-Genoulaz, V., Gruat-La-Forme, F. A., Millet, P. A., Seville, M., Boucher, X., Derrouiche, R., Llerena, D., Neubert, G., Pellegrin, C., (2005) Questionnaire d'enquête sur les pratiques de partage d'informations par une entreprise participant à une chaîne logistique établie.Projet COPILOTES, Région Rhône-Alpes, www.copilotes.eu

[17] Klein, R., (2007) Customization and real time information access in integrated eBusiness supply chain relationships. Journal of Operations Management, 25 pp. 1366-1381.

[18] Ganesan, S., (1994) Determinants of long-tem orientation in buyer seller relationships. Journal of Marketing, 58, pp. 50-69.

[19]Gulati, R., (1995) Does familiarity breed trust? the implications of repeated ties for contractual choice alliances. Academy of Management Journal, 38, pp. 85-112.

[20] Fynes, B., Voss, C., Seán, d. B., (2005) The impact of supply chain relationship quality on quality performance. International Journal of Production Economics, 96 (3), pp. 339-354

[21] Sakka, O., Botta-Genoulaz, V., Trilling, L., (2008) Pratiques d'échanges d'information et pratiques collaboratives pour la performance des chaînes logistiques. Mémoire de Master, INSA de Lyon, 41 p.

[22] Modi, S. B., Mabert, V. A., (2007) Supplier development: Improving supplier performance through knowledge transfer. Journal of Operations Management, 25 pp. $42-64$. 